\title{
Optimization and Stress Analysis of Underground Oil Pipelines in High and Steep Slope Areas
}

\author{
Kun Huang ${ }^{1}$, Jin $\mathrm{Wu}^{1,{ }^{*}}$, Meilin $\mathrm{Hu}^{2}$, Han Xiang ${ }^{3}$ and Zhihao Zhang ${ }^{1}$ \\ ${ }^{1}$ School of Petroleum Engineering, Southwest Petroleum University, Chengdu, China \\ ${ }^{2}$ PetroChina Kunlun Gas Ltd. of Yunnan, Kunming, China \\ ${ }^{3}$ Chengdu E Ga Petroleum Engineering Technology Co., LTD of Sichuan, Chengdu, China
}

\begin{abstract}
Underground oil pipelines are made of pressurized pipes, and when damage occurs, the consequences can be disastrous. Pipeline accidents caused by stress can be attributed to material corrosion, impractical design, manufacturing defect, environmental damage, and man-made destruction. In this study, by utilizing the stress analysis software CAESAR II, the stress of pipelines in high and steep slope areas was analyzed under the same operating conditions and different piping technologies. Comparing the different simulation consequences of each pipeline technology, an optimized laying process was proposed to reduce the stress of underground oil pipelines in high and steep slope areas; this process was named Sectional Pipe Laying Process. According to the results of CAESAR II, the stress and movement of underground oil pipelines in high and steep slope areas were drastically reduced and the safety greatly enhanced.
\end{abstract}

Keywords: CAESAR II, high and steep slope areas, stress, underground oil pipeline.

\section{INTRODUCTION}

Pipeline systems, one of the most important aspects of crude oil transportation, have always been seen as the arteries of the oil energy industry, and the safe and effective operation of these arteries is vitally important. In 2006, a crude oil pipeline leakage accident happened in Alaska's Prudhoe Bay. In 2011, in the capital city of Kenya, an oil pipeline rupture killed 75 people and injured more than 100. In 2013, an oil pipeline rupture and deflagration accident killed 62 people and injured more than 100 in China.

Due to the expanding development of oil pipelines across the globe, laying pipelines along areas including valleys, rivers, seismic fault lines, swamp regions, and high and sleep slope regions are becoming more necessary and frequent. However, the safety of oil pipelines laid in complex areas is threatened by various factors such as natural hazards, local stress, and man-made sabotage. Out of these complex areas, the most dangerous areas are high and sleep slopes. The gradient of a slope is at least $40^{\circ}$ and sometimes reaches $90^{\circ}$, and its security is more important than pipelines running through level ground. Therefore, it is necessary to analyze the stress of underground oil pipelines in these areas to optimize the laying process.

In this study, underground oil pipelines in high and steep slope areas were researched. By analyzing and studying oil pipeline accidents in specific areas, the stress failure modes

*Address correspondence to this author at the School of Petroleum Engineering, Southwest Petroleum University No. 8, XinduRoad, Xindu District, Chengdu, Sichuan Province China; Tel:13648015885;

E-mails: casiou@163.com; 821679058@qq.com were divided into several types including ductile failure (high stress damage), brittle failure (low stress damage), stress corrosion damage, fatigue damage, and creep damage. Ductile failure is most likely to occur, according to present conditions, in our country. As such, ductile failure of underground oil pipelines in high and steep slope areas was researched for this paper.

In 2014, Wu Xiaonan, Lu Hongfang, and Huang Kun researched the stress of natural gas pipelines in earthquake zones based on spectrum analysis. They concluded that under the action of an earthquake, both the largest axial and longitudinal movement zones were at the top of slopes, and it is extremely necessary to check the stress and movement of buried natural gas pipelines when designing pipelines in sloped areas [1].

In addition, Wu Xinguo, Zhou Qiao, and Lu Hongfang studied the stress of underground oil pipelines using the finite element analysis software CAESAR II. The results suggested that under any piping process, bends are the danger points for pipeline stress, and under different working conditions, the causes of stress can be different [2].

Recently, Li Ting, Wu Shijuan, and Huang Kun optimized the process design of pipelines by researching the stress of natural gas pipelines in mountainous areas based on CAESAR II results. It was found that the stress value of natural gas pipelines in mountainous areas can be effectively reduced by using the newly developed "ladder style" laying process, and as the number of ladders increases, the average stress value decreases [3].

According to the above-mentioned reports, the main threats to underground oil pipelines in high and steep slope 
areas include earthquakes, fault lines, landslides, thermal expansion, and deformation under the action of gravity. In this article, the influence on pipeline security caused by the deformation and stress of oil pipelines in high and steep slope areas was the focus. According to a real underground oil pipeline situation in a high and steep slope area of YUN NAN province, we simulated and established this oil pipeline model. All this section of pipeline is buried, and the soil around the pipe makes a full and pressure contact with the pipeline. The model is shown in Fig. (1).

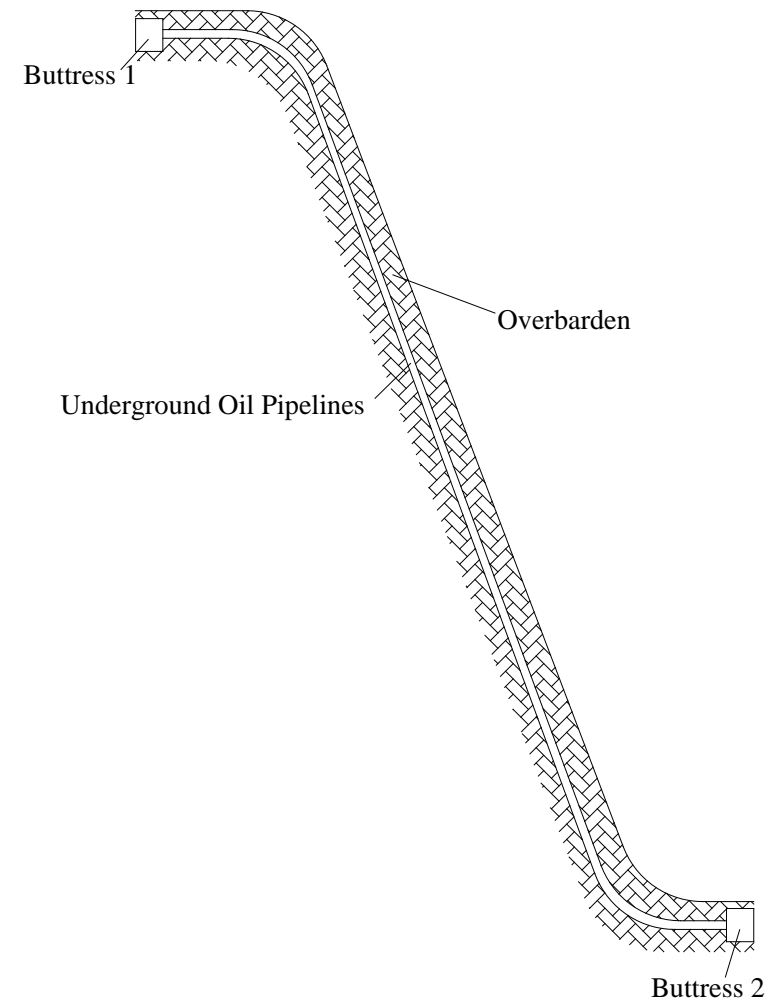

Fig. (1). Structure diagram of an oil pipeline in high and steep slope area.

\section{CALCULATION AND CRITERIA OF STRESS ON OIL PIPELINES}

According to ASME B31.4-2012 Pipeline Transportation Systems for Liquids and Slurries, the circumferential, longitudinal, shear, and equivalent stress must be considered. The pipeline stresses in loops, bends, and offsets should be calculated based on the total range from minimum to maximum expected temperatures, regardless of whether the bends are heat-stewed or not. In this study, the stress caused by internal pressure, thermal expansion, and piping subsidence were considered [4-6].

The restrained pipeline was researched, and the allowable values for restrained pipeline system stress are illustrated in Table 1.

\section{METHODS}

The influencing factors of stress include material properties, loads, and natural conditions. Generally, there are three methods to analyze the stress of buried pipelines: analytic method, experiment method, and numerical method.

The analytic method uses the function expression to establish a mathematical model for the practical problem, and results are obtained through mathematical analysis. However, this method is only accurate for simple questions.

The experimental method uses specific physical and chemical methods to determine the value of stresses in a prototype or simplified model. This method can basically obtain the correct stress value, but the errors can be large, and the process is tedious.

The numerical method can achieve numerical solutions for function values of discrete points, and is generally divided into the finite difference method and the finite element method. For piping stress analysis, the finite element method was used. The finite element method is a numerical solution that disperses the continuum to finite element, and uses the technology of electronic computers to get results. The results produced by this method are more accurate, and can be applied to most research fields of oil pipelines.

In general, the finite element method analysis software includes AUTOPIPE, CAESAR II, CAEPIPE, PIPESTESS, PIPE-FLO, and SIMFLEX. The software is primarily used to simulate, analyze, and visualize a practical structure under different conditions of pipelines. In this study, CAESAR II was used to study the stress of oil pipelines in high and steep slope areas [7].

\section{ORIGINAL MODEL}

A length of underground oil pipeline in a high and steep slope area was illustrated as the object of experimental analysis. The conditions of this length of pipeline included gravity, temperature, and the internal pressure. $W$ is the gravity stress load, $T$ is the temperature stress load, and $P$ is the internal pressure stress load. The working loads can be found by:

$$
L_{1}=W+T+P
$$

Table 1. Allowable values for restrained pipeline system stresses.

\begin{tabular}{|c|c|c|c|c|c|}
\hline Location & $\begin{array}{c}\text { Internal and } \\
\text { External } \\
\text { Pressure Stress, } \\
S_{H}\end{array}$ & $\begin{array}{c}\text { Allowable } \\
\text { Expansion } \\
\text { Stress, } S_{E}\end{array}$ & $\begin{array}{c}\text { Additive } \\
\text { Longitudinal } \\
\text { Stress, } S_{L}\end{array}$ & $\begin{array}{c}\text { Sum of Longitudinal } \\
\text { Stresses from } \\
\text { Sustained and } \\
\text { Occasional Loads }\end{array}$ & $\begin{array}{c}\text { Equivalent } \\
\text { Combined } \\
\text { Casing or Uncased Pipe } \\
\text { Stress, } S_{\text {eq }}\end{array}$ \\
\hline \hline $\begin{array}{c}\text { Restrained } \\
\text { Pipeline }\end{array}$ & $0.72 S_{y}$ & $0.90 S_{y}$ & $0.90 S_{y}$ & $0.90 S_{y}$ & $0.90 S_{y}$ \\
Crossings
\end{tabular}

Note: $S_{y}=$ specified minimum yield strength of pipe material, psi (MPa) 
The horizontal length, the vertical height, and the total length of the pipeline was $63.3 \mathrm{~m}, 174.0 \mathrm{~m}$, and $185.2 \mathrm{~m}$, respectively. The slope angle was $71.2^{\circ}$ (for convenience, the slope angle was assumed to be $70^{\circ}$ for this study). Both ends of this pipeline are buttress, in other words, the two ends of this pipeline have no linear displacement and angular displacement. Besides, the pipeline will be exerted many kinds of force from the soil, such as stress and friction between the surface of the pipeline and the soil.

According to the design specifications, the installation temperature and the operating temperature of the oil pipeline were $20^{\circ} \mathrm{C}$ and $85^{\circ} \mathrm{C}$, respectively, and thus the temperature variation was $65^{\circ} \mathrm{C}$. In addition, the operating pressure was $12 \mathrm{MPa}$, the radius of the heat-stewed bend was $8,130 \mathrm{~mm}$. The other basic parameters of the oil pipeline in the original model are illustrated in Table 2.

According to the security assessment report of the oil pipeline in the described area, the soil was hard clay, and the friction factor was 0.6 . The other basic parameters of the soil model are determined by the detection of soil samples, and the results are illustrated in Table 3 [6].

In order to simulate the stress distribution of the buried oil pipeline in the soil more effectively, the acting force of the buttress to the pipeline was simplified to one kind of fixed constraint. Moreover, the acting force of the soil to the pipeline was simplified to the friction of the $\mathrm{X}$ axis and the elastic force of the $\mathrm{Y}$ and $\mathrm{Z}$ axes.

The model was divided into 23 segments along the direction of the pipeline, and each segment was 10 meters in length [8] (Fig. 2). Fixed constraints were set at Nodes 10 and 230. At the same time, the soil constraint determined by the parameters in Table $\mathbf{3}$ was added to the original model of oil pipeline.

Through the static analysis of CAESAR II, the values of the bend stress, the code stress, the stress percent (the percentage of the ratio of the code stress and the allowable stress), the linear movements of each node, the angular movements of each node, the maximum stress nodes, and the maximum movement nodes were discovered. The code stress and the linear movements of each node are shown in Fig. (3).

The highest value of code stress appeared at the nodes at $24 \mathrm{~m}$ and $211 \mathrm{~m}$ along the pipeline direction, and they were
338.7436 MPa and 347.3189 MPa, respectively. The highest value of code stress reached $10 \%$ of the allowable stress, and the consequences would be terrible if a torrential flood, earthquake, or debris flow occurred.

\section{DISCUSSION}

\subsection{The Influence Factors of Code Stress}

Normally, two terminals of a buried pipeline in high and steep slope areas would have buttresses to make this pipeline a semi-open system. In this system, the linear movements, angular movements, and code stress were not influenced by an adjacent pipeline. Thus, the height of the slope and the slope gradient became the key factors influencing the code stress value of this pipeline [9].

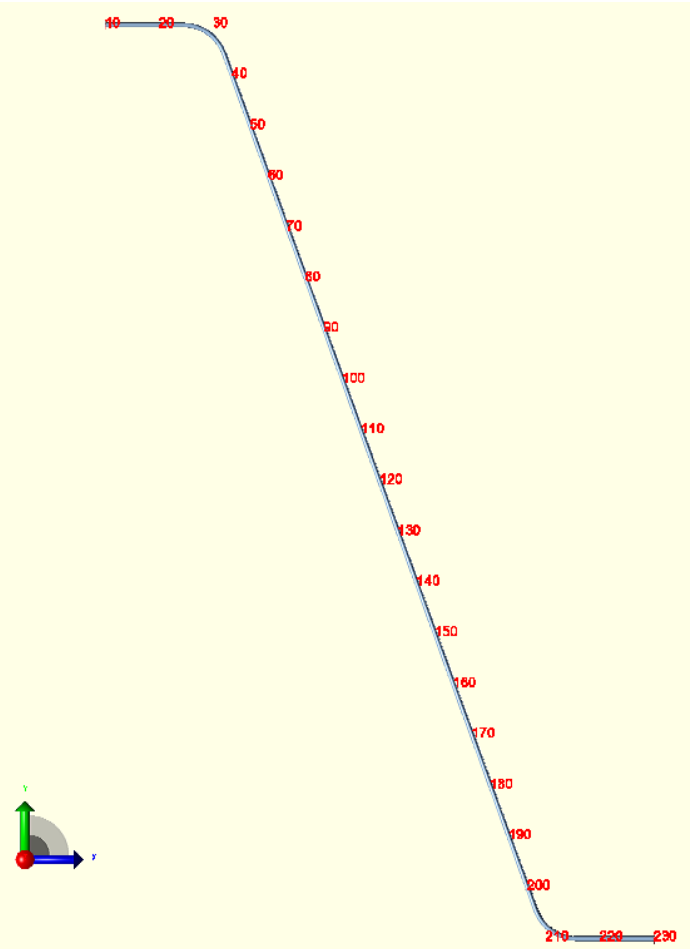

Fig. (2). Original model of an oil pipeline in a high and steep slope area.

In order to confirm how the two factors affected the code stress of this pipeline, finite element analysis was used to

Table 2. Basic parameters of the original model of oil pipeline

\begin{tabular}{|c|c|c|c|c|c|c|}
\hline Material & Diameter (mm) & $\begin{array}{c}\text { Wall Thickness } \\
\mathbf{( m m )}\end{array}$ & $\begin{array}{c}\text { Fluid Density } \\
\mathbf{( k g / \mathbf { m } ^ { 3 } )}\end{array}$ & $\begin{array}{c}\text { Minimum Yield } \\
\text { Strength (MPa) }\end{array}$ & $\begin{array}{c}\text { Allowable Stress } \\
\mathbf{( M P a )}\end{array}$ & $\begin{array}{c}\text { Thickness of } \\
\text { insulating layer } \\
\mathbf{( m m )}\end{array}$ \\
\hline \hline API 5L X70 & 813 & 24 & 850 & 482 & 347 \\
\hline
\end{tabular}

Table 3. Basic parameters of the soil model

\begin{tabular}{|c|c|c|c|c|c|c|}
\hline $\begin{array}{c}\text { Soil Density } \\
\left(\mathbf{k g} / \mathbf{c m}^{\mathbf{3}}\right)\end{array}$ & $\begin{array}{c}\text { Buried } \\
\text { Depth } \mathbf{( c m )}\end{array}$ & $\begin{array}{c}\text { Internal friction } \\
\left.\text { Angle } \mathbf{(}^{\circ}\right)\end{array}$ & $\begin{array}{c}\text { Soil Compaction } \\
\text { Multiplier }\end{array}$ & $\begin{array}{c}\text { Thermal Expansion } \\
\text { Coefficient }\end{array}$ & $\begin{array}{c}\text { Yield displacement } \\
\text { factor }\end{array}$ & $\begin{array}{c}\text { Temperature } \\
\text { variation }\left({ }^{\circ} \mathbf{C}\right)\end{array}$ \\
\hline \hline 0.0017 & 120 & 30 & 5 & 0.015 & 11.214 & 65 \\
\hline
\end{tabular}




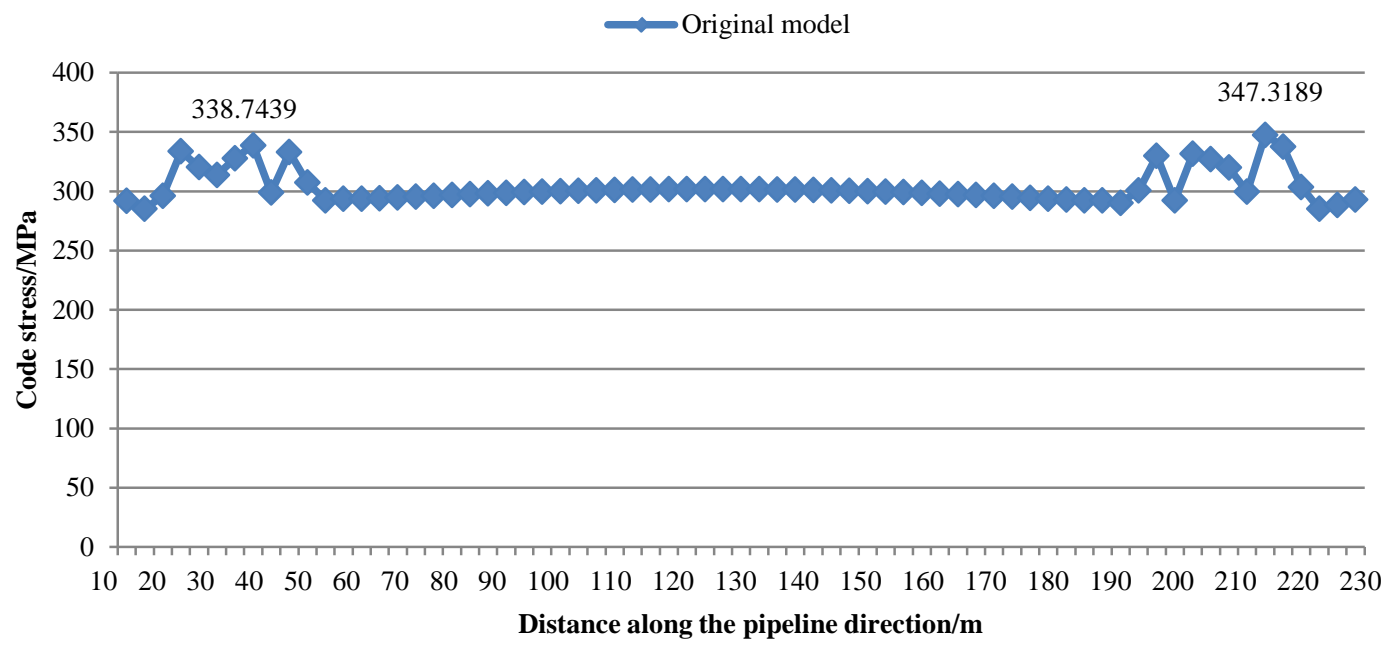

Fig. (3). Code stress of the original model in a high and steep slope area.

Table 4. Code stress of the pipeline with different values of slope gradient.

\begin{tabular}{|c|c|c|c|c|c|}
\hline The slope gradient $\left({ }^{\circ}\right)$ & $\mathbf{6 0}^{\circ}$ & $\mathbf{6 5}^{\circ}$ & $\mathbf{7 0}^{\circ}$ & $\mathbf{7 5}^{\circ}$ & $\mathbf{8 0}^{\circ}$ \\
\hline \hline The largest code stress (MPa) & 355.21 & 351.10 & 347.32 & 345.33 & 344.02 \\
\hline
\end{tabular}

Note: The height of the slope was $169.1442 \mathrm{~m}$

Table 5. Code stress of the pipeline with different values of the height of slope.

\begin{tabular}{|c|c|c|c|c|}
\hline The height of the slope (m) & $\mathbf{1 5 0 . 3 5 0 4}$ & $\mathbf{1 5 9 . 7 4 7 3}$ & $\mathbf{1 6 9 . 1 4 4 2}$ & $\mathbf{1 8 7 . 9 3 8 0}$ \\
\hline \hline The largest code stress (MPa) & 339.25 & 343.44 & 347.32 & 357.01 \\
\hline
\end{tabular}

Note: The slope gradient was $70^{\circ}$

quantitatively analyze the factors. By setting different values for one factor and keeping the value of the other factor the same, the difference between each result with different set values were tested and analyzed; the results are shown in Tables $\mathbf{4}$ and $\mathbf{5}$.

It was concluded that the code stress of the buried oil pipeline increased with an increasing value of the height of the slope and decreased with an increasing value of the slope gradient. In other words, the value of the code stress of this pipeline could be decreased by enhancing the value of the slope gradient or reducing the value of the height.

\subsection{Optimization Model}

In this study, the height of the slope and the slope gradient were changed to optimize the original model [3]. A sectional model of a buried oil pipeline was established, shown in Fig. (4), and the value of the horizontal length and the vertical height of the slope were kept the same. The slope was divided into two equal segments, and a length of horizontal pipeline was inserted between the two slope segments. In order to turn the two slope segments of the pipeline into a mutually independent pipeline, a fixed buttress was added in the middle (Node 130 in Fig. 4) of the inserted horizontal pipeline.

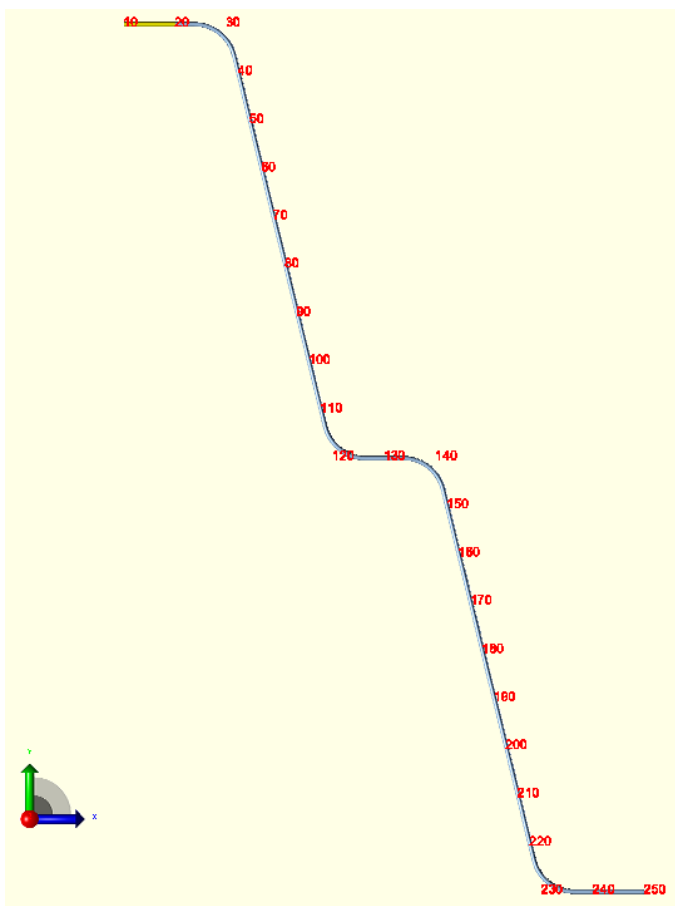

Fig. (4). Optimization model of oil pipeline in a high and steep slope area. 


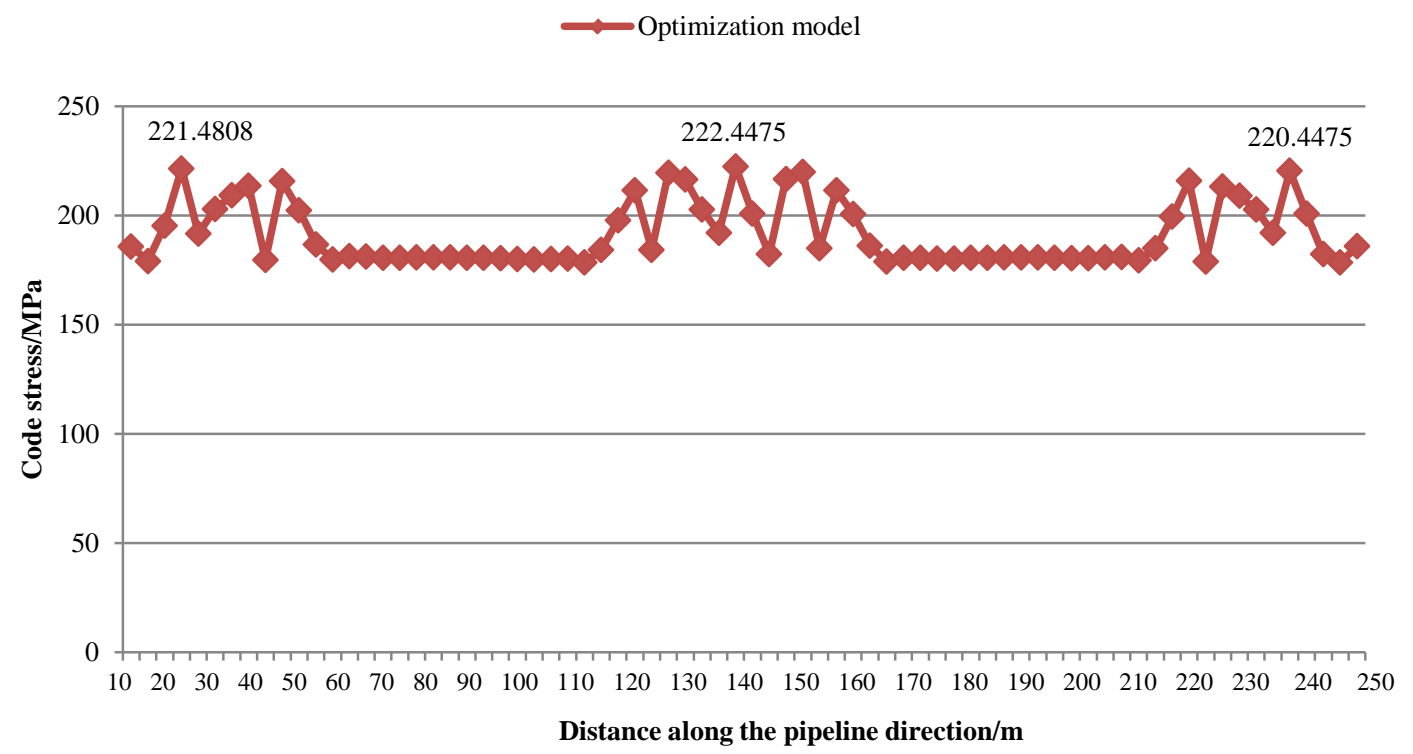

Fig. (5). Code stress of the optimization model in a high and steep slope area.

The integral model was divided into 25 segments along the direction of the pipeline. Each horizontal segment of the pipeline was $10 \mathrm{~m}$ and each diagonal segment of the pipeline was $9.677 \mathrm{~m}$. The slope gradient of this optimization model was $76.12^{\circ}$. Like the original model, fixed constraints were added at Nodes 10, 130, and 250, and the soil constraint was determined by the parameters in Table $\mathbf{3}$ for the oil pipeline optimization model. The values of code stress are illustrated in Fig. (5).

As can be seen in Fig. (5), the increasing number of roasted bends led to an increasing number of peak values of code stress, and the largest code stress nodes appeared in the nodes at $20 \mathrm{~m}, 130 \mathrm{~m}$, and $240 \mathrm{~m}$. The values of the largest code stress of these nodes were $221.4808 \mathrm{MPa}, 222.4475$ $\mathrm{MPa}$, and 220.4475MPa, respectively.

The stress percentages of both the original model and the optimization model are shown in Fig. (6).

As shown in Fig. (6), the highest stress percentage of the original model was $79.96 \%$ and the average stress percent of the original model was $69.78 \%$, while the highest stress percent and the average stress percent of the optimization model were $51.22 \%$ and $44.04 \%$, respectively. All the values of stress percentage of the optimization model met the criteria for underground oil pipelines in ASME B31.4-2012

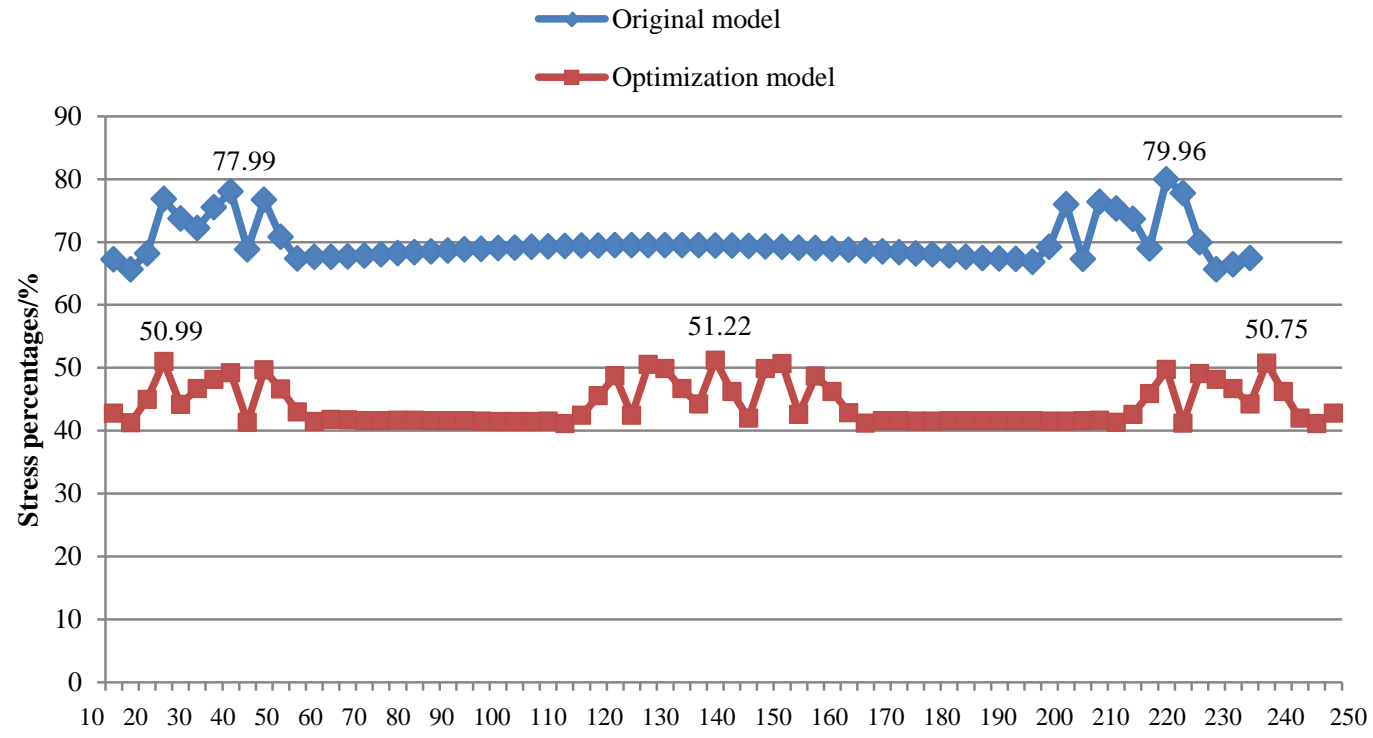

Distance along the pipeline direction/m

Fig. (6). Stress percentages of original model and optimization model. 


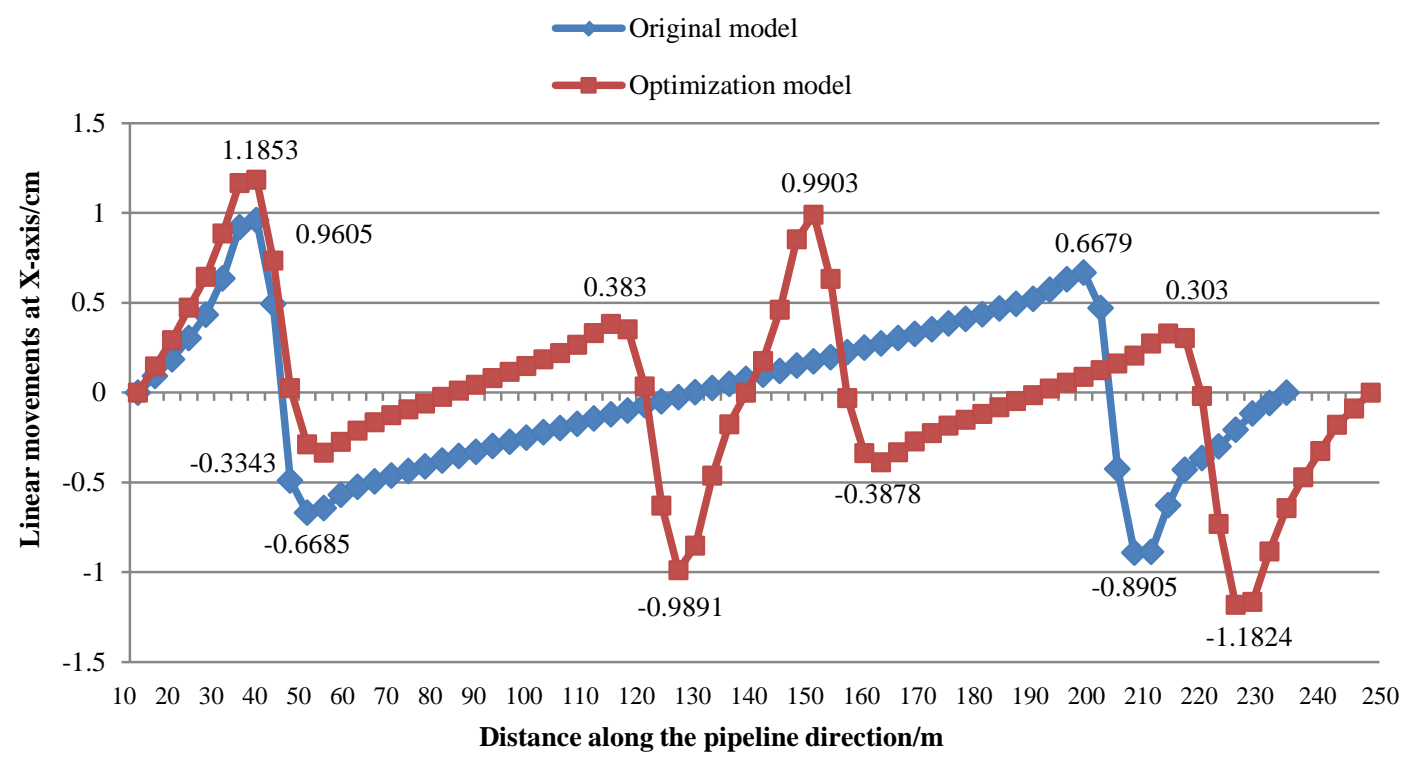

Fig. (7). Linear movements of the original model and optimization model at the $\mathrm{X}$-axis.

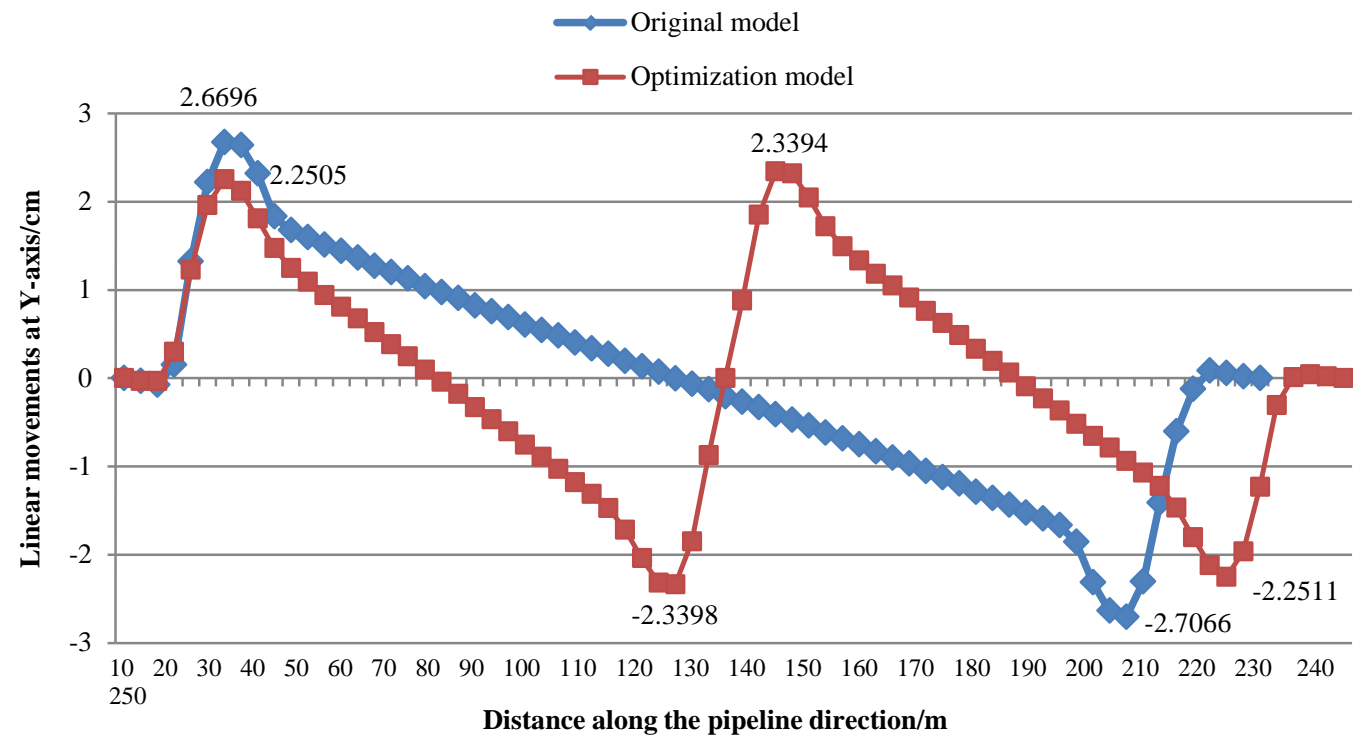

Fig. (8). Linear movements of the original model and optimization model at the Y-axis.

Pipeline Transportation Systems for Liquids and Slurries.

In this study, both the original model and the optimization model were established on a vertical plane, so there were no angular movements at the $\mathrm{X}$-axis and $\mathrm{Y}$-axis, and no linear movements at the Z-axis. The linear movements at the $\mathrm{X}$-axis and $\mathrm{Y}$-axis and the angular movements at the Z-axis are illustrated in Figs. (7-9), respectively.

\section{CONCLUSION}

(1) Stress analysis software CEASAR II calculated the values of the stress and movements of each node of the pipeline in working conditions with internal and external loads, and with the software, a stress analysis report for the security of a pipeline was obtained.

(2) This sectional pipe laying process distinctly reduced the largest code stress, the average stress percent, the linear movements at the $\mathrm{X}$-axis and $\mathrm{Y}$-axis, and the angular movements at the $\mathrm{Z}$-axis, and reduced the highest code stress by about $30 \%$. Thus, the optimization design effectively improved the security of the pipeline.

(3) As the security of a pipeline increases, the number of fixed buttresses, the depths of the trenches, and the difficulty of construction also increase. Economy and safety should be considered in all practical engineering applications. 


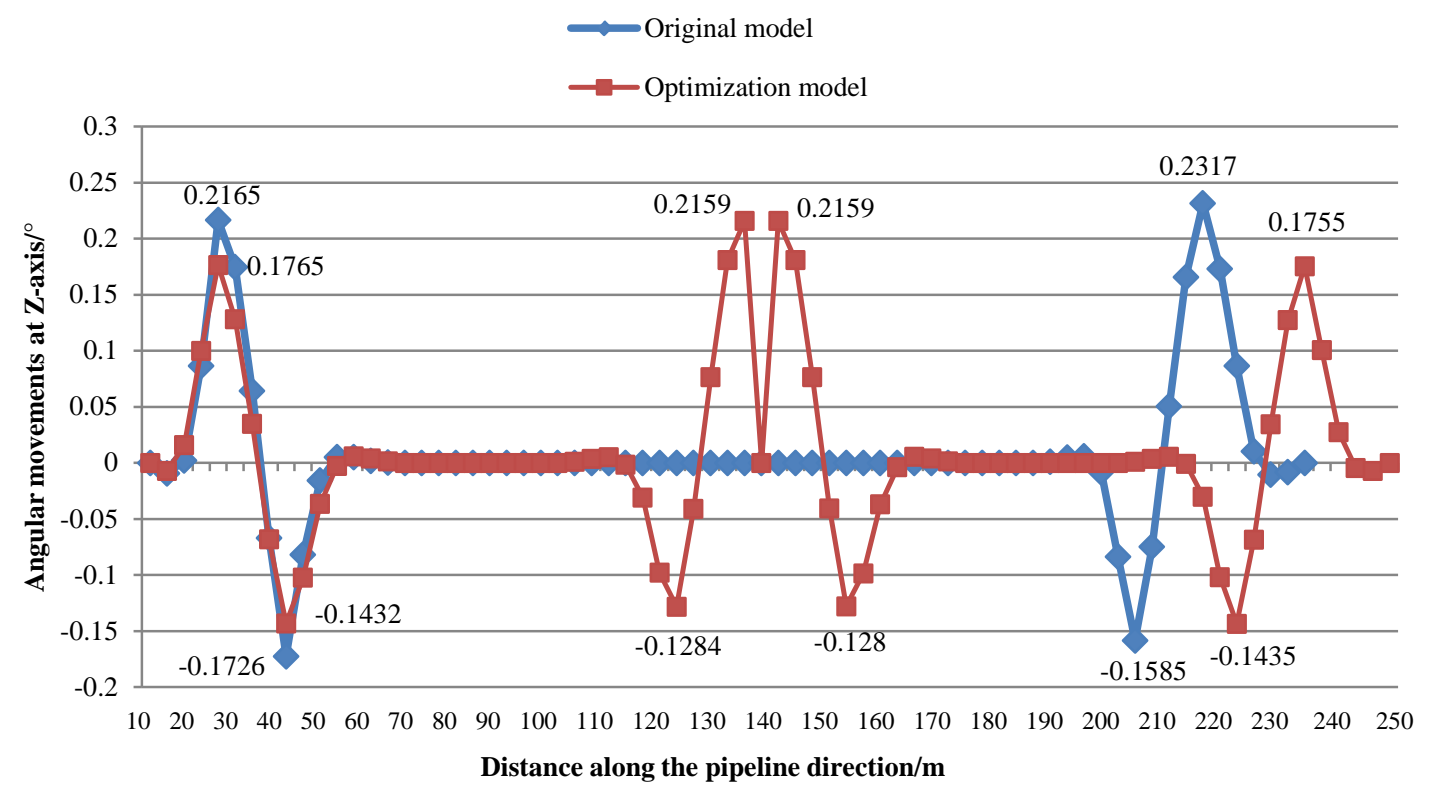

Fig. (9). Angular movements of the original model and optimization model at the Z-axis.

\section{CONFLICT OF INTEREST}

The authors confirm that this article content has no conflict of interest.

\section{ACKNOWLEDGEMENTS}

Decleared none.

\section{REFERENCES}

[1] X. N. Wu, H. F. Lu, and K. Huang, "Stress analysis of gas pipelines at seismic belts based on the spectrum analysis", Natural Gas Industry, vol. 34, pp. 152-157, May 2014.

[2] X. G. Wu, Q. Zhou, and H. F. Lu, "Stress Analysis of CAESAR IIbased underground oil pipelines", Pipeline Technique and Equipment, vol. 21, pp. 16-18, March 2014.
[3] T. LI, S. J Wu, and K. Huang, "Research on stress reduction measures in mountainous areas", Pipeline Technique and Equipment, vol. 3, pp. 7-8, March 2014.

[4] J. Shuai, and G. J. Yu, The Strength Design of Pipeline and Storage Tank, Petroleum Industry Press, Beijing, 2010.

[5] ASME B31.4-2012 Pipeline Transportation Systems for Liquids and Slurries. American Society of Mechanical Engineers Press, New York, 2010.

[6] S. A. Liu, H. Y. Pu, and H. Jiang, "Stress analysis methods of buried pipeline", Oil and Gas Storage and Transportation, vol. 51, no. 4, pp. 274-278, April 2012.

[7] X. D. Sha, X. H. Chen, and K. Huang, "Analysis on stress influence factors on natural gas pipeline”, Natural Gas and Oil, vol. 31, no. 1, pp. 1-4, January 2013.

[8] X. Jiang, T. Y. Wang, and L. Sun, "Stress analysis on natural gas pipeline without covering in high and steep slope areas", Natural Gas and Oil, vol. 12, pp. 26-30, December 2013.

[9] K. Huang, S. J. Wu, and H. F. Lu, "Stress analysis on natural gas pipeline laid along the slope,” Natural Gas and Oil, vol. 30, no. 4, pp. 1-4, April 2012.

(c) Huang et al.; Licensee Bentham Open.

This is an open access article licensed under the terms of the Creative Commons Attribution Non-Commercial License (http://creativecommons.org/licenses/ by-nc/3.0/) which permits unrestricted, non-commercial use, distribution and reproduction in any medium, provided the work is properly cited. 